\title{
Sex-specific interaction between $A P O E$ genotype and carbohydrate intake affects plasma HDL-C levels: the Strong Heart Family Study
}

\author{
M. J. Mosher $\cdot$ L. A. Lange $\cdot$ B. V. Howard \\ E. T. Lee $\cdot$ L. G. Best - R. R. Fabsitz \\ J. W. MacCluer • K. E. North
}

Received: 24 July 2007 / Accepted: 5 December 2007/Published online: 29 March 2008

(C) Springer-Verlag 2008

\begin{abstract}
Low plasma levels of high-density lipoprotein cholesterol (HDL-C) are identified as a risk factor for cardiovascular disease (CVD). Sexual dimorphism, however, is widely reported in both HDL-C and CVD, with the underlying explanations of these sexual differences not fully understood. HDL-C is a complex trait influenced by both genes and dietary factors. Here we examine evidence for a sex-specific effect of $A P O E$ and the macronutrient carbohydrate on HDL-C, triglycerides (TG) and apoprotein A-1 (ApoA-1) in a sample of 326 male and 423 female participants of the Strong Heart Family Study (SHFS). Using general estimating equations in SAS to account for kinship correlations, stratifying by sex, and adjusting for age, body mass index (BMI) and SHS center, we examine the relationship between $A P O E$ genotype and carbohydrate intake on circulating levels of HDL-C, TG, and ApoA-1
\end{abstract}

M. J. Mosher

Department of Anthropology, Western Washington University, Bellingham, WA, USA

M. J. Mosher ( $\bowtie)$

Lab of Biological Anthropology, University of Kansas, Lawrence, KS, USA

e-mail: mjmosher@email.unc.edu; mjmosher@aol.com

L. A. Lange

Department of Genetics, University of North Carolina, Chapel Hill, NC, USA

B. V. Howard

MedStar Research Institute, Washington, DC, USA

E. T. Lee

Center for American Indian Health Research, College of Public Health, University of Oklahoma, University of Oklahoma Health Sciences Center,

Oklahoma City, OK, USA through a series of carbohydrate-by-sex interactions and stratified analyses. APOE-by-carbohydrate intake shows significant sex-specific effects. All males had similar decreases in HDL-C levels associated with increased carbohydrate intake. However, only those females with APOE-4 alleles showed significantly lower HDL-C levels as their percent of carbohydrate intake increased, while no association was noted between carbohydrate intake and HDL-C in those females without an APOE-4 allele. These findings demonstrate the importance of understanding sex differences in gene-by-nutrient interaction when examining the complex architecture of HDL-C variation.

Keywords APOE - Carbohydrate $\cdot$ HDL-C $\cdot$ Lipids . Interaction

\section{G. Best}

Missouri Breaks Industries Research, Inc.,

Timber Lake, SD, USA

R. R. Fabsitz

Epidemiology and Biometry Program,

National Heart, Lung, and Blood Institute,

Bethesda, MD, USA

\section{J. W. MacCluer}

Department of Genetics,

Southwest Foundation for Biomedical Research,

San Antonio, TX, USA

K. E. North

Department of Epidemiology and Carolina Center for Genome Sciences, University of North Carolina, Chapel Hill, NC, USA 


\section{Introduction}

Dietary manipulation of plasma cholesterol levels is widely accepted as a primary step in the treatment of dyslipidemias and prevention of their sequelae of atherosclerosis and cardiovascular disease (CVD). Past dietary recommendations to lower plasma cholesterol emphasized a low-fat diet with a higher intake of complex carbohydrate, yet studies vary in the extent to which either macronutrient influences lipoprotein risk factors $[25,27,45,62]$. The low-fat diet has not proven universally effective in lowering risk profiles [77], suggesting an underlying genetic variation in dietary response [56]. Moreover, diets high in carbohydrate intake are frequently shown to decrease plasma levels of highdensity lipoprotein (HDL) cholesterol (HDL-C) [14, 42] and increase circulating triglycerides (TG) [59]. Such an inverse correlation between plasma triglycerides and HDL-C is widely reported across populations, despite dietary differences [53]. High-density lipoprotein (HDL) is the major lipoprotein of the reverse cholesterol transport system thought to be protective against atherosclerosis. HDL-C is viewed as an indicator of the efficacy of this reverse transport system [12]. The inverse relationship of carbohydrate intake to HDL-C was introduced over 20 years ago [68], with studies indicating that this relationship began in early childhood [72]. Growing evidence supports the presence of the cardio-protective role of higher plasma HDL [3, 49]. Long-term studies now suggest that low-fat, high carbohydrate diets may have exacerbated current problems of obesity, type II diabetes, and the metabolic syndrome [77]. These factors show an association with lower HDL in both males and females [20,74, 78]. Variation in carbohydrate effects on lipid risk factors may indeed be influenced by the quality of the carbohydrate [59] or other population-specific factors $[46,69]$. Although the current dietary recommendations now focus on quality rather than the quantity of carbohydrate, protein and fat intake [1, 4, 41], the results from studies of dietary relationship to plasma lipids remain inconsistent. The issue of sex-specific variation as a factor in the response of plasma lipids to variation in dietary macronutrients appears consistently in many studies, however $[16,40,58]$. We hypothesize that a genetic predisposition and sexual dimorphism may explain some of the variation in response of HDL-C levels to dietary carbohydrate intake $[47,51]$.

Apoproteins are the major protein moiety of plasma lipoproteins and responsible for a variety of roles including stimulation of the synthesis of lipoproteins, cofactors for lipoprotein modulating enzymes, and ligands for lipoprotein receptors. Our candidate gene, apoprotein $E(A P O E)$ has a major polymorphism with three major alleles $(e 2, e 3$, and $e 4$ ). The accepted wild type is $e 3$ ( $>60 \%$ in all populations studied), with $e 2$ and $e 4$ distinguished by a one base-pair substitution at different locations; $e 4\left(\mathrm{Cys}_{112}\right.$ to $\left.\mathrm{Arg}\right)$ and $e 2$ ( $\operatorname{Arg}_{158}$ to Cys) $[10,21,76]$. The three resulting isoforms have well-documented variation in functional effects [43, 70]. APOE is a ligand for several cell membrane receptors of the triglyceride-laden low-density lipoproteins chylomicrons and VLDL. APOE also assists in cholesterol efflux from macrophages and mediates uptake of the reverse transport lipoprotein, HDL [11, 49]. Using the binding capacity of E3 as the referent, studies indicates that E2 has an impaired binding, while studies of E4 report somewhat inconsistent results, with E4 binding either similarly to E3 [10] or at an enhanced capacity [2]. Research further suggests preferential binding of E4 to large triglyceride-rich very-low-density lipoproteins (VLDL), while E2 and E3 show preference to the HDL [9].

The plasma lipoprotein response of $A P O E$ genotype to dietary fat and cholesterol has been extensively examined, while the response to variation in carbohydrate intake has been virtually ignored until recently $[57,58]$. Sex-specific associations are documented between $A P O E$ variants and plasma lipoproteins $[17,57,65]$ and between $A P O E$ variants and the risk of CVD [35]. Current research demonstrates the benefits of examining $A P O E$ within the context of a sexstratified approach in order to develop a clear picture of gene action on each of the plasma lipoproteins [73]. Here we examine the sex-specific relationship of $A P O E$ alleles and the dietary percent of carbohydrate intake on plasma levels of HDL-C, TG, and apoprotein A-1 (ApoA-1), a primary component in regulating the biosynthesis of HDL [60].

\section{Methods}

Sample

The Strong Heart Study (SHS) is a longitudinal study to determine CVD risk factors among 13 American Indian tribes in three geographical areas across the central plains and the southwest. The Institutional Review Board (IRB) of the Indian Health Service, and the collaborating education institutions approved the study protocol. Initiated in 1989, this study completed baseline exams between 1989 and 1992. The exams consisted of personal interviews, anthropometrics, and physical exams including laboratory tests. Original participants, aged 45-74, included individuals diagnosed for diabetes [28]. The Strong Heart Family Study (SHFS), a component of the SHS, is a family study that has recruited and examined more than 3,800 individuals in multiple extended families. Between 1997 and 1999, a subset of family study participants, including 320 males and 421 females ages 18-88, completed prompted 24-h dietary recalls and gave fasting blood samples for lipid profiles and genotyping [55]. This subset is the sample used for this study. 


\section{Phenotyping}

Phenotyping for plasma lipoproteins, apoproteins, triglycerides, insulin and glucose was completed from blood samples drawn after a 12 hour fast. Assays were performed at the MedStar Research Institute, following standard laboratory procedures described elsewhere (http://strongheart. ouhsc.edu/manual/PhaseV/Vol01.pdf) [37]. HDL-C, triglycerides (TG), apoprotein A-1, were determined using enzymatic reagents and the Hitachi 717 (Boehringer Mannheim Diagnostics), while LDL-C was determined using the Friedewald equation for individuals with $\mathrm{TG}<$ $400 \mathrm{mg} / \mathrm{dl}$. For those participants with $\mathrm{TG}>400 \mathrm{mg} / \mathrm{dl}$, the LDL was directly assessed $[15,54]$. Fasting insulin was determined through a modified method of the polyethylene glycol-double antibody radioimmunoassay [36], and glucose levels were assayed through the hexokinase method (Glucose-HK: Beohringer Mannheim Diagnostics, Indianapolis, IN), also on the Hitachi 717 [54]. APOE phenotypes were determined using $2 \mathrm{~h}$ of isoelectric focusing followed by immunoblotting to identify $A P O E$ bands [31, 33] and used to infer genotypes [48].

Body mass index (BMI) was calculated by Quetelet's index: weight $(\mathrm{kg}) /$ height $(\mathrm{m})^{2}$ [38]. These measures of weight and height were both sampled with participants wearing light clothing and no shoes [28]. The percent of body fat was determined through an impedance meter and equations based upon total body water [26]. Dietary profiles were collected using an interview-prompted 24 hour recall. Nutrient data were determined from these dietary recalls using nutrient data system [67]. Macronutrient intake was assessed as the percent of total caloric intake and includes the percent of fat $(9 \mathrm{kcal} / \mathrm{gm})$, protein and carbohydrate (both $4 \mathrm{kcal} / \mathrm{gm}$ ). Carbohydrates were not differentiated into complex and simple carbohydrate, and are therefore not categorized for glycemic index [30, 72].

Diabetes status was defined by three categories: those without diabetes, those diagnosed with diabetes and those with impaired glucose tolerance, ascertained by fasting glucose and insulin levels. The categories were in accordance with the World Health Organization criteria of 1980 and detailed in a strong heart study publication by Kataoka et al. [32].

\section{Statistical analyses}

Data were initially examined with multivariate analyses in SPSS 11.5, analyzing both unadjusted lipoprotein measures (HDL and TG log-transformed) and standardized residuals of lipids after adjustment by the basic model. Dietary intake was categorized into sex-stratified tertiles of macronutrient intake. Results were then verified within the SAS software system (SAS Institute, version 8.0, Cary, NC) in order to implement general estimating equations (GEE). These GEE models and mixed model analysis of variance (ANOVA) allow tests of association while accounting for the correlation among members within common pedigrees. We are reporting results obtained using GEE models in this paper.

$A P O E$ allele frequencies were estimated by gene counting, and the familial-based data were evaluated for Mendelian inconsistencies and cleaned of pedigree errors using PREST and the effects of genotyping error using Simwalk II, both described in detail elsewhere, [54, 71, 75] and (http://strongheart.ouhsc.edu/manual/PhaseV/). Individuals were grouped into two categories, those without an $e 4$ allele and those with an $e 4$ allele. As the frequency of individuals with at least one $e 2$ allele was minimal and similar for both males and females, they were consolidated within the corresponding study categories, with or without $e 4$. Therefore, genotype $e 3 / 2$ was included with $e 3 / 3$, and $e 4 / 2$ included with may $e 3 / 4$ and $e 4 / 4$. No homozygote $e 2 /$ 2 was noted in the sample.

We assessed the association between carbohydrate intake, genotype, and their interaction on HDL-C, TG and APOA-1, using mixed model analysis of variance for continuous, normally distributed traits and generalized estimating equations (GEE) for categorical traits. The GEE method estimates within-pedigree similarity of residuals to reestimate regression parameters and thus calculate more accurate standard errors [22]. We specified an exchangeable correlation structure for these analyses, which should have been slightly conservative. Analyses were completed on the sex-stratified analyses and tests of genotype-by-sex interaction, diet-by-sex, genotype-bydiet, and genotype-by-diet-by-sex interaction were performed. We used two levels of covariate adjustment: (a) base model: SHS center, age, BMI; and (b) a fully adjusted model that includes the base model adjustment factors, with the additional factors of body fat, fasting insulin, glucose levels and diabetes status. Continuous outcomes were first examined for adherence to distributional assumptions (including approximate normality of error terms conditional on covariates and homoscedasticity) and appropriate transformations were made when necessary. Specifically, HDL-C and TG were natural logtransformed. $P$ values $\leq 0.05$ were deemed statistically significant.

\section{Results}

Descriptive statistics

Table 1 present the descriptions of this Strong Heart Family Study sample as a whole, with adiposity and 
Table 1 Characteristics of Strong Heart Family participants

\begin{tabular}{|c|c|c|c|}
\hline Trait & Mean (SE) & Mean (SE) & $P$ value \\
\hline Age (years) & $39.5(1.3)$ & $40.1(1.2)$ & 0.60 \\
\hline $\mathrm{BMI}^{\mathrm{a}}$ & $32.9(1.0)$ & $34.1(0.9)$ & 0.027 \\
\hline $\mathrm{BF}^{\mathrm{b}}(\%)$ & $31.2(1.1)$ & $43.3(1.1)$ & $<0.001$ \\
\hline $\mathrm{FG}(\mathrm{mg} / \mathrm{dl})$ & $123.2(5.2)$ & $125.8(5.0)$ & 0.72 \\
\hline FI (mIU/l) & $26.9(3.3)$ & $28.4(3.2)$ & 0.075 \\
\hline \multicolumn{4}{|l|}{ Diabetes status } \\
\hline Diabetic (\%) & 20.7 & 24.9 & 0.052 \\
\hline IGT $(\%)$ & 9.9 & 6.7 & 0.073 \\
\hline \multicolumn{4}{|l|}{ Lipids } \\
\hline $\mathrm{TC}(\mathrm{mg} / \mathrm{dl})$ & $180.9(3.4)$ & $174.0(3.3)$ & 0.008 \\
\hline HDL (mg/dl) & $42.0(1.5)$ & $45.2(1.5)$ & $<\mathbf{0 . 0 0 1}$ \\
\hline \multicolumn{4}{|l|}{$\mathrm{HDL} \mathrm{AHA}^{\mathrm{c}}$} \\
\hline$<40(\%)$ & 54.8 & 44.6 & 0.075 \\
\hline $41-59(\%)$ & 36.6 & 43.6 & 0.095 \\
\hline$>60(\%)$ & 8.6 & 11.8 & 0.26 \\
\hline $\mathrm{LDL}(\mathrm{mg} / \mathrm{dl})$ & $117.1(2.4)$ & $109.1(2.2)$ & $<\mathbf{0 . 0 0 1}$ \\
\hline TG (mg/dl) & $136.6(5.3)$ & $123.0(4.9)$ & 0.029 \\
\hline APOA-1 (mg/dl) & $1.3(0.03)$ & $1.37(0.03)$ & $<\mathbf{0 . 0 0 1}$ \\
\hline \multicolumn{4}{|l|}{ Dietary $^{\mathrm{d}}$} \\
\hline Total (Kcal) & $2,303.6(58.7)$ & 1,899.1(52.5) & $<\mathbf{0 . 0 0 1}$ \\
\hline Carb (\%) & $50.3(0.9)$ & $52.8(0.8)$ & 0.005 \\
\hline Prot $(\%)$ & $14.4(0.3)$ & $13.9(0.3)$ & 0.65 \\
\hline Fat $(\%)$ & $34.2(0.7)$ & $33.9(0.7)$ & 0.24 \\
\hline
\end{tabular}

${ }^{\text {a }} \mathrm{BMI}=\mathrm{kg} / \mathrm{m}^{2}$

${ }^{\mathrm{b}} \mathrm{BF}=$ body fat (\% of body composition)

${ }^{c}$ HDL-AHA $=$ risk categories $\%$ of population

${ }^{\mathrm{d}}$ Dietary traits $=$ percent of total daily caloric intake

e $P$ values were determined using generalized linear mixed models (continuous outcomes) and generalized estimating equations (categorical outcomes), which controlled for the correlation among members in the same pedigrees

$\mathrm{FG}=$ fasting glucose, $\mathrm{FI}=$ fasting insulin- $\%$ of sample, Diabetes status $=$ diabetes and IGT (impaired glucose tolerance) $\%$ of population

diabetes related traits, lipid profiles, and dietary data for both males and females. Participants' ages ranged from 1889 years, with a mean of 39 years for both males and females. A total of $54 \%$ of the males and $62 \%$ of the females had BMI scores $\geq 30$ (data not shown), indicating a substantial proportion of obese individuals in this sample [34]. As expected, the percent of body fat was higher in females than males. Sexual dimorphism was also present in the plasma lipids, with females exhibiting significantly higher circulating levels of HDL-C and APOA-1 and lower levels of TG, LDL-C and total cholesterol (TC). Dietary differences between males and females were statistically significant only for total caloric intake and carbohydrate percent of total intake, with females taking in fewer
Table 2 Frequency of APOE alleles and genotypes in both males and females

\begin{tabular}{|c|c|c|c|c|}
\hline & \multicolumn{2}{|c|}{ Males $(n=321)$} & \multicolumn{2}{|c|}{ Females $(n=423)$} \\
\hline & $n$ & Frequency & $n$ & Frequency \\
\hline \multicolumn{5}{|c|}{ APOE alleles } \\
\hline $\mathrm{e} 2$ & 13 & 0.02 & 15 & 0.02 \\
\hline e3 & 539 & 0.84 & 732 & 0.87 \\
\hline e4 & 90 & 0.14 & 101 & 0.12 \\
\hline \multicolumn{5}{|c|}{ Genotypes } \\
\hline $2 / 2$ & 0 & 0.000 & 0 & 0.000 \\
\hline $2 / 3$ & 11 & 0.003 & 13 & 0.003 \\
\hline $3 / 3$ & 225 & 0.701 & 315 & 0.745 \\
\hline $3 / 4$ & 78 & 0.243 & 89 & 0.210 \\
\hline $4 / 2$ & 2 & 0.006 & 1 & 0.002 \\
\hline $4 / 4$ & 5 & 0.002 & 5 & 0.001 \\
\hline
\end{tabular}

calories but a higher percent in carbohydrate than males. The percent of individuals experiencing diabetes or impaired glucose tolerance was 30.6 for males, 31.6 for females (Table 1).

$A P O E$ allele and genotype frequencies are shown in Table 2. Further delineation of characteristics between $A P O E$ study categories identified distinct genotypic differences (Table 3), using least squared means to account for the covariates within the data. Males carrying the $e 4$ allele had significantly increased BMI and body fat, without a significant difference in total calorie intake or nutrient intake. Levels of fasting insulin were higher in males with e4. In contrast, no significant differences were noted in females for adiposity-related characteristics or diabetesrelated traits. Both males and females carrying an $e 4$ allele exhibited lower HDL-C and APOA-1 levels, however, the effects of genotype were more pronounced in AHA HDL risk categories in females than males.

\section{Main effect of diet}

In the initial analyses with SPSS, only carbohydrate intake remained consistently associated with any lipid measure, and specifically only with HDL-C (data not shown). We changed to SAS with GEE to accommodate any effect for pedigrees and identified the main effect of carbohydrate intake on HDL-C and TG variation to be statistically significant in males only (see Table 4). Findings were consistent for carbohydrate intake regardless of covariate adjustment, in both the base model and the fully adjusted model (additionally adjusted for body fat, diabetes status, fasting insulin and glucose levels). Carbohydrate intake was not associated with APOA-1 variation in either males or females. 
Main effect of genotype

Genotypic differences were noted in HDL-C and APOA-1 levels, with significantly lower levels in both males and females carrying the $e 4$ allele (Table 3 ). After the adjustment for covariates, only APOA-1 remained significantly different for both males and females, while the main effect of $A P O E$ remained statistically significant for HDL-C in females only. No effect of $A P O E$ genotype was significant for TG levels (Table 4).
Interaction between diet and genotype

Because sex-specific effects of diet and genotype were observed, we assessed the evidence for diet-by-genotype interaction in males and females separately. Interaction between carbohydrate intake and $A P O E$ genotype in variation in HDL-C levels was observed in females only, in both the base and fully adjusted models (Table 4). Plasma HDL-C levels of females without an $e 4$ allele showed no association with carbohydrate intake, whereas females

Table 3 Characteristics of individuals stratified by APOE genotypes

\begin{tabular}{|c|c|c|c|c|c|c|}
\hline & \multicolumn{2}{|l|}{ Males } & \multirow[t]{2}{*}{$P^{\mathrm{e}}$} & \multicolumn{2}{|l|}{ Females } & \multirow[t]{2}{*}{$P^{\mathrm{e}}$} \\
\hline & Without $e 4(n=236)$ & With $e 4(n=85)$ & & Without $e 4(n=329)$ & With $e 4(n=94)$ & \\
\hline Trait & LS-Mean (SE) & LS-Mean (SE) & & LS-Mean (SE) & LS-Mean (SE) & \\
\hline Age (year) & $39.3(0.9)$ & $36.5(1.6)$ & 0.12 & $40.6(1.3)$ & $39.5(1.8)$ & 0.51 \\
\hline $\mathrm{BMI}^{\mathrm{a}}$ & $32.3(0.9)$ & $34.6(1.2)$ & 0.009 & $33.8(1.2)$ & $35.6(1.4)$ & 0.12 \\
\hline $\mathrm{BF}^{\mathrm{b}}(\%)$ & $30.9(1.1)$ & $33.3(1.3)$ & 0.012 & $42.9(1.2)$ & $44.1(1.4)$ & 0.18 \\
\hline $\mathrm{FG}(\mathrm{mg} / \mathrm{dl})$ & $115.9(4.1)$ & $122.8(6.3)$ & 0.24 & $130.0(7.2)$ & $126.9(8.8)$ & 0.79 \\
\hline FI (mIU/l) & $28.8(4.2)$ & $33.4(5.1)$ & 0.042 & $24.8(1.4)$ & $26.3(2.7)$ & 0.25 \\
\hline \multicolumn{7}{|l|}{ Diabetes status } \\
\hline Diabetic (\%) & 18.6 & 26.0 & 0.17 & 25.2 & 23.4 & 0.63 \\
\hline $\operatorname{IGT}^{\mathrm{c}}(\%)$ & 10.6 & 7.0 & 0.33 & 6.4 & 6.4 & 0.99 \\
\hline \multicolumn{7}{|l|}{ Lipids } \\
\hline $\mathrm{TC}(\mathrm{mg} / \mathrm{dl})$ & $180.0(3.6)$ & $178.8(4.9)$ & 0.74 & $176.0(3.7)$ & $175.6(4.8)$ & 0.92 \\
\hline HDL (mg/dl) & $43.7(1.7)$ & $39.5(2.1)$ & 0.029 & $45.3(1.6)$ & $41.6(1.9)$ & 0.012 \\
\hline \multicolumn{7}{|l|}{ HDL-AHA } \\
\hline$<40(\%)$ & 51.7 & 61.2 & 0.13 & 41.6 & 53.4 & 0.004 \\
\hline $41-59(\%)$ & 37.3 & 35.2 & 0.56 & 44.4 & 40.4 & 0.15 \\
\hline$>60(\%)$ & 10.6 & 3.5 & 0.11 & 13.4 & 6.4 & 0.024 \\
\hline LDL (mg/dl) & $115.4(3.0)$ & $118.6(4.1)$ & 0.44 & $109.9(2.2)$ & $113.2(3.2)$ & 0.29 \\
\hline TG (mg/dl) & $130.2(7.3)$ & $141.8(10.1)$ & 0.10 & $126.8(5.0)$ & $121.4(7.7)$ & 0.62 \\
\hline APOA-1 (mg/dl) & $1.33(0.03)$ & $1.21(0.03)$ & $<\mathbf{0 . 0 0 1}$ & $1.38(0.04)$ & $1.29(0.04)$ & 0.004 \\
\hline \multicolumn{7}{|l|}{ Dietary $^{\mathrm{d}}$} \\
\hline Total (Kcal) & $2,373(85)$ & $2,112(128)$ & 0.075 & $1,914(50)$ & $1,816(91)$ & 0.65 \\
\hline Carb (\%) & $50.2(1.0)$ & $50.4(1.5)$ & 0.88 & $52.2(0.8)$ & $53.2(1.3)$ & 0.45 \\
\hline Prot $(\%)$ & $14.3(0.4)$ & $15.0(0.6)$ & 0.46 & $14.0(0.3)$ & $13.8(0.5)$ & 0.67 \\
\hline Fat $(\%)$ & $34.3(0.9)$ & $32.9(1.3)$ & 0.28 & $34.4(0.6)$ & $33.8(1.0)$ & 0.57 \\
\hline
\end{tabular}

Genotypes pooled into two groups: those without $e 4$ and those with $e 4$ allele. $P$ values indicate significant differences between genotypes, within $\operatorname{sex}$

${ }^{\mathrm{a}} \mathrm{BMI}=\mathrm{kg} / \mathrm{m}^{2}$

${ }^{\mathrm{b}} \mathrm{BF}=$ body fat

c IGT = impaired glucose tolerance

${ }^{\mathrm{d}}$ Dietary traits $=$ percent of total daily Kcal intake

e Significant $P \leq 0.05$ in generalized linear mixed models (continuous outcomes) or generalized estimating equations (categorical outcomes), which controlled for the correlation among members in the same pedigrees

$\mathrm{FG}=$ fasting glucose, $\mathrm{FI}=$ fasting insulin 
Table $4 P$ values for tests of main effects and interaction of sex, $A P O E$ and carbohydrate, with table representing results of maximum model (basic adjustment and adjustment for measures of diabetes, body fat, glucose and fasting insulin)

\begin{tabular}{|c|c|c|c|c|}
\hline & $\begin{array}{l}\text { Gender } \times \text { Carb. } \\
\times \text { ApoE } \\
\text { interaction }^{\mathrm{a}}\end{array}$ & $\begin{array}{l}\text { Carb. } \\
\times \text { ApoE } \\
\text { interaction }^{\mathrm{b}}\end{array}$ & $\begin{array}{l}\text { Carb. } \\
\text { main } \\
\text { effects }\end{array}$ & $\begin{array}{l}\text { ApoE } \\
\text { main } \\
\text { effects }^{\mathrm{c}}\end{array}$ \\
\hline \multicolumn{5}{|l|}{$\log (\mathrm{HDL})$} \\
\hline Sex-combined & 0.0002 & & & \\
\hline Males & & 0.14 & 0.029 & 0.17 \\
\hline Females & & 0.0003 & 0.11 & 0.0006 \\
\hline \multicolumn{5}{|l|}{$\log ($ ApoA1) } \\
\hline Sex-combined & 0.060 & & & \\
\hline Males & & 0.084 & 0.14 & $<0.0001$ \\
\hline Females & & 0.063 & 0.56 & 0.0023 \\
\hline \multicolumn{5}{|l|}{ Log(trigs) } \\
\hline Sex-combined & 0.58 & & & \\
\hline Males & & 0.47 & 0.018 & 0.54 \\
\hline Females & & 0.92 & 0.53 & 0.60 \\
\hline
\end{tabular}

Adjustments made for basic model, then incremental additions with measures of diabetes, body fat, and fasting insulin and glucose levels. Interaction models adjusted for all lower order terms. Basic model adjusted for age, SHS center, BMI; Maximum model adjustment for 2 diabetes variables (s3adadm and s3adaifg), body fat (s3fat), glucose (s3g0) and fasting insulin (s3insu). Models with interactions are adjusted for all lower order terms

${ }^{a}$ Performed on sex-combined sample

${ }^{b}$ Performed on sex-stratified samples

${ }^{c}$ Performed on sex-stratified samples only if $P$ value for carb $\times$ $A P O E$ interaction was not significant in the previous model

carrying an e4 allele demonstrated a highly significant association. In contrast, an inverse relationship between HDL-C and carbohydrate intake was noted in males, but no effect modification by APOE genotype was observed (Fig. 1). No effect of interaction was noted in either sex for TG or APOA-1 levels, regardless of covariate adjustment.

\section{Discussion}

Sexual dimorphism of HDL-C levels and CVD is widely reported in many populations, yet underlying mechanisms for these differences are not fully understood. Controlling for age, SHS center and BMI, fasting blood sugar and insulin levels, and diabetic status, we identified an interaction between sex, APOE genotype, and carbohydrate intake on plasma HDL-C levels. This gene-by-macronutrient interaction was restricted to the female SHFS participants. As dietary manipulation of plasma lipids is the initial strategy in CVD prevention, identifying factors which affect circulating HDL-C may support the ability to implement more effective individually-tailored dietary intervention.

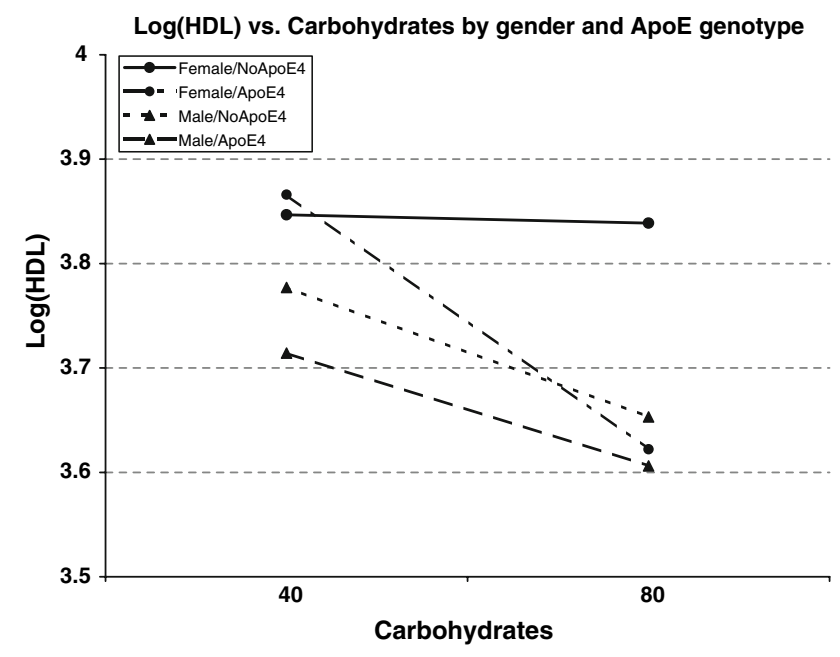

Fig. $1 \log (\mathrm{HDL})$ versus carbohydrates by gender and ApoE genotype

HDL remains an important risk modifier in cardiovascular diseases. Beyond its putative role of sequestering and transporting cholesterol and other detrimental products back to the liver for disposal, HDL is believed to inhibit endothelial inflammation and promote production of endothelial nitric oxide (NO) and prostacyclins [39]. Variation in HDL levels is believed to be primarily associated with variation in clearance, except in dietary studies which have identified that fat intake affects HDL production or transport rates [61]. Although we cannot identify the specific metabolic effects on HDL-C variation here, as plasma levels of APOA-1 are not associated with carbohydrate intake, our findings suggest that catabolism may be the more likely mechanism affecting HDL-C variation in this study. Moreover, with carbohydrate intake not the traditionally studied macronutrient for association with $A P O E$, our findings demonstrate the importance of including carbohydrate intake in a sex-specific context, when examining the genetic and dietary influence underlying HDL-C variation.

\section{Genotype effects}

APOE polymorphisms and their distinct isoforms are the most widely studied of the apoproteins. The Strong Heart Study population exhibits a higher frequency of the wild type $e 3$ and lower frequencies of $e 2$ and $e 4$ than seen in many populations worldwide $[32,50]$, yet a profile similar to other American and Mexican Indian populations [8, 19]. Acting as the major ligand for clearance of triglyceride-rich lipoproteins and HDL through cellular receptors, $A P O E$ function may vary depending upon the lipoprotein with which it is connected and include additional anti-atherogenic properties [60,63]. Dallongeville et al. meta-analyses of studies from 17 countries evaluated the relationship of 
APOE with plasma cholesterol. Reporting consistent findings in the relationships, the authors suggested variation in amplitude of effect between populations. No clear association was noted between HDL-C and those $A P O E$ phenotypes carrying one allele of $e 2$, however, HDL-C variation between individuals with $e 3 / 3, e 3 / 4$, and e4/4 was reported. Additionally, aside from the expected association of $e 2$ with elevated TG, these authors also reported a significant association of higher TG and lower HDL-C with the heterozygote e3/4 genotypes than in lipid levels of homozygotes $e 3 / 3$ and $e 4 / 4$. Moreover, they stressed that these relationships remained consistent in a variety of populations including children, diabetics, obese, and hyperlipidemic individuals [7]. However, while this study did include both males and females, it did not address sexspecific variation. Hallman's nine country study reported consistent associations of APOE genotype with total cholesterol levels among the countries, despite assumed dietary differences. No direct measure of any dietary variable was included in that study, nor were the data sex-stratified [21].

Kataoka et al. [32] study examining the relationship of $A P O E$ polymorphisms to plasma lipids in the original Strong Heart Study individuals $(n=4,410)$, reported sexspecific variation associated with $A P O E$ polymorphisms. Genotype was not significantly associated with HDL-C variation in males (ages 45-64), however, in females, a significant trend for HDL-C levels was noted in all female subgroups studied: normal and diabetic, premenopausal and menopausal. HDL-C was higher in females carrying an $e 2$ and lower in individuals carrying an $e 4$ than for females with $e 3 / 3$ genotypes. Genotype variation was noted for TG differences in males only, with $e 2$ and $e 4$ having higher TG levels than males homozygous for $e 3 / 3$ genotype in both normal and diabetic individuals. Dietary factors were not considered in the study [32].

Many other studies document sex-specific effects of $A P O E$ on plasma lipids in a variety of populations, although various lipid effects are not consistent throughout the studies $[13,18,44,50,52,64,66]$. The complexity of the interrelatedness of the lipid system with its constant remodeling of lipoproteins, makes study comparisons difficult. The relationship of $A P O E$ to lipids has been shown to be age and context dependent, with increased heterogeneity of variance in older participants attributable to cumulative environmental effects reflecting greater variation in diet, exercise and other factors. Unique environmental variation is offered as an explanation for some inconsistencies [52]. A recent review article proposed that gender and hyperglycemia were two of the primary environmental factors affecting the APOE-HDL-C relationship [18], which points to variation in carbohydrate intake and metabolism as moderating factors in HDL-C variation.
Dietary effects

The varied relationships between carbohydrate intake and plasma HDL-C have long been acknowledged in the literature [42, 68]. The recent focus on macronutrient quality emphasizing complex carbohydrates, to include both soluble and insoluble dietary fibers, has sparked renewed interest in physiological responses to carbohydrate intake. Traditional dietary studies examining nutrient association with lipid profiles concentrated on fatty acids and cholesterol intake, and most studies examined males only [58]. Few studies have quantified sex-specific variation directly, choosing instead to adjust for any sex differences and suggest that the discrepancies between studies may be based on unidentified sex variation in dietary response [5]. This approach of adjusting for sex differences has been challenged for genetic studies by Stengard et al. [73] who suggest that pooling sex data results in findings which do not adequately reflect the genotype effects on phenotypic variation in either sex.

Differences between sexes were reported in the National Health and Nutrition Examination Study (NHANES III, 1988-1994), with higher carbohydrate intake associated with lower HDL in males and elevated TG in females, BMI in both males and females, and glucose levels in males only [80]. In our study, the main effect of carbohydrate intake was significantly associated with lower HDL-C and higher TG in males only, after adjustment for BMI and traits associated with glucose levels.

\section{Interaction of $A P O E$ and carbohydrate}

Polymorphisms of $A P O E$ have been shown to affect variation in plasma lipid profiles when associated with dietary nutrients. Traditionally, studies have examined cholesterol and fat intake and indicated that individuals with an $e 4$ allele have greater plasma lipid sensitivity in LDL and TG to dietary variation [18]. Most reported studies of dietAPOE interaction are documented in males only [58]. Our study compared males and females of similar backgrounds and families to identify a sex-specific $A P O E$ genotype vulnerability to carbohydrate effects on HDL-C levels in females only, a vulnerability which remained consistent after adjusting for center, age, adiposity and glucose altering traits. We used additional analyses on these data, defining carbohydrate intake in sex-stratified tertiles and applying a general linear model in SPSS 11.5 to substantiate these findings (results not shown).

Several studies have shown little variation in lipid patterns between hyperglycemic and diabetic groups when comparing $A P O E$ genotypes across quintiles of glucose levels. One, however, reported $A P O E$-serum glucose interaction affecting variation in HDL-C and APOA-1 in 
both males and females, and TG in males only [18]. Adjusting for the basic model and each glucose altering trait separately did not alter our outcome (Table 4), and APOA-1 variation was not affected by carbohydrate intake in either males or females in any of our models.

The association pattern of HDL-C with APOE polymorphisms in our study reflected Kataoka et al's findings in females, and only when carbohydrate was a factor. We believe that these findings reinforce the importance of further examining the relationship of carbohydrate intake to HDL variation. Most importantly, these findings support our hypothesis that genetic predisposition and sexual dimorphism are in fact present in the response of HDL-C to carbohydrate intake (Fig. 1).

Two issues must be noted here: (a) the between sex variation noted in individuals carrying the common $e 3$, and (b) within sex HDL-C variation of APOE genotypes seen in females. The first might be explained through sexual dimorphism noted in lipid metabolism, with females showing a greater sensitivity to insulin's antilipolytic effects, and suppression of postprandial plasma fatty acid concentrations to compensate for their higher basal fatty acid flux [47]. The second issue may be connected to $e 4$ as an effective ligand for triglyceride-rich lipoproteins (TRL), and high levels of APOE in HDL-C appearing to accelerate the lipoprotein's catabolism [29]. Animal research suggests a further option of variation in $A P O E$ isoforms during recycling of (TRL), a process stimulated by HDL. While APOE3 is readily resupplied to plasma HDL particles during TRL recycling, thus serving to maintain HDL levels and further enhance hepatic clearance of remnants, APOE4 is believed to accumulate intracellularly. Therefore, APOE4 is not readily recycled and reattached to HDL particles, thereby resulting in a decrease of HDL as well as decreasing recycling of TRL [24]. Addressing these specific issues is beyond the scope of this paper, yet our findings may suggest a sex-specific component at that level. The Heeren study did not address sex-specific variation. Determining HDL-C subfractions in future research to address such questions as whether the preferential binding of $A P O E$ isoforms and variation in reclycling of these isoforms is present in American Indian populations, or how carbohydrate affects variation in specific HDL-C subfractions with and without association to $A P O E$ genotypes, may identify underlying explanations for our results. Furthermore, such information may also indicate whether dietary lowering of HDL-C actually reduces its cardioprotective properties.

Metabolically active adipose tissue may have contributed to our findings. Body fat was significantly higher in both males and females with APOE4 allele, despite lower caloric intake. Our adjustment for body fat cannot account for variation in levels of adipokines [82] or the HDL scavenger receptor class B type I (SR-BI) which is highly expressed in adipose tissue [6]. Furthermore, sexual dimorphism has been widely documented in both adipose tissue levels and patterns, its hormones leptin and adiponectin [81, 82], and energy homeostasis [79] all of which are influenced by nutritional status and affect energy balance, carbohydrate and lipid metabolism and insulin resistance [23, 47].

In this study we are limited by a cross-sectional approach, the lack of specific information of HDL subfractions and the subjective approach of recall as a measure of dietary exposure. However, while cross-population studies suggesting consistency among populations of $A P O E$ effects on lipid variation in the face of inferred dietary differences [21], this study incorporates a quantified dietary variable and a sex-stratified approach in a larger population. Whether the findings of this study reporting sex-specific variation of HDL-C as an effect of carbohydrate-APOE polymorphism interaction are applicable to other populations will depend on future research. Our findings demonstrate the importance of understanding sex differences in gene-by-nutrient interaction when examining the complex architecture of HDL-C variation.

\section{Summary}

In conclusion, we identified sex-specific gene-by-nutrient effects on HDL-C in American Indian participants of the SHFS. Males, regardless of their APOE genotype, consistently demonstrated an inverse relationship between carbohydrate intake and plasma HDL-C levels. In contrast, genotype-by-carbohydrate-specific associations were shown in females. Only those females with an $e 4$ allele demonstrated the inverse relationship between carbohydrate intake and HDL-C levels widely documented in many populations, whereas those females without an $e 4$ allele showed no relationship of HDL-C to increased levels of carbohydrate intake.

Acknowledgements We thank the Strong Heart Family Study participants. Without their participation, this project would not have been possible. In addition, the cooperation of the Indian Health Service hospitals and clinics and the directors of the SHS clinics, and the many collaborators and staff of the Strong Heart Study have made this project possible. Supported by NHLBI cooperative agreement that includes U01 grants HL65520, HL 41642, HL41654, and HL65521 and the Cardiovascular Training Grant, NHLBI, T32-HL007055. The views expressed in this paper are those of the authors and do not necessarily reflect those of the Indian Health Service.

\section{References}

1. Astrup A (2001) Healthy lifestyles in Europe: prevention of obesity and type II diabetes by diet and physical activity. Public Health Nutr 4(2B):499-515 
2. Brown W (2007) High-density lipoprotein and transport of cholesterol and triglyceride in blood. J Clin Lipidol 1:7-19

3. Bruckert E (2006) Epidemiology of low HDL-cholesterol: results of studies and surveys. Eur Heart J Suppl 8(Suppl F):F17-F22

4. Chan GKD, the ACPM Policy Committee (2002) Diet in the prevention and control of obesity, insulin resistance, and Type II diabetes, College of Preventive Medicine, Washington DC

5. Couture P, Archer WR, Lamarche B, Landry N, Deriaz O, Corneau L, Bergeron J, Bergeron N (2003) Influences of apolipoprotein E polymorphism on the response of plasma lipids to the ad libitum consumption of a high-carbohydrate diet compared with a high-monounsaturated fatty acid diet. Metabolism 52(11):1454-1459

6. Dagher G, Donne N, Klein C, Ferre P, Dugail I (2003) HDLmediated cholesterol uptake and targeting to lipid droplets in adipocytes. J Lipid Res 44(10):1811-1820

7. Dallongeville J, Lussier-Cacan S, Davignon J (1992) Modulation of plasma triglyceride levels by apoE phenotype: a meta-analysis. J Lipid Res 33(4):447-454

8. Demarchi DA, Salzano FM, Altuna ME, Fiegenbaum M, Hill K, Hurtado AM, Tsunetto LT, Petzl-Erler ML, Hutz MH (2005) APOE polymorphism distribution among Native Americans and related populations. Ann Hum Biol 32(3):351-365

9. Dong LWK (1996) Human apolipoprotein E4 domain interaction. J Biol Chem 271(Aug 9):19053-19057

10. Eichner JE, Dunn ST, Perveen G, Thompson DM, Stewart KE, Stroehla BC (2002) Apolipoprotein E polymorphism and cardiovascular disease: a HuGE review. Am J Epidemiol 155(6): 487-495

11. Farkas MH, Weisgraber KH, Shepherd VL, Linton MF, Fazio S, Swift LL (2004) The recycling of apolipoprotein E and its aminoterminal $22 \mathrm{kDa}$ fragment: evidence for multiple redundant pathways. J Lipid Res 45:1546-1554

12. Fazio SLM (2006) Editorial: sorting out the complexities of reverse cholesterol transport: CETP polymorphism, HDL and coronary disease. J Clin Endocrinol Metab 91(90):3273-3275

13. Ferrieres J, Sing CF, Roy M, Davignon J, Lussier-Cacan S (1994) Apolipoprotein E polymorphism and heterozygous familial hypercholesterolemia. Sex-specific effects. Arterioscler Thromb 14(10): $1553-1560$

14. Ford ES, Liu S (2001) Glycemic index and serum high-density lipoprotein cholesterol concentration among us adults. Arch Intern Med 161(4):572-6

15. Friedewald WT, Levy RI, Fredrickson DS (1972) Estimation of the concentration of low-density lipoprotein cholesterol in plasma, without use of the preparative ultracentrifuge. Clin Chem 18:499-502

16. Frikke-Schmidt R (2000) Context-dependent and invariant associations between APOE genotype and levels of lipoproteins and risk of ischemic heart disease: a review. Scand J Clin Lab Invest Suppl 233:3-25

17. Frikke-Schmidt R, Nordestgaard BG, Agerholm-Larsen B, Schnohr P, Tybjaerg-Hansen A (2000a) Context-dependent and invariant associations between lipids, lipoproteins, and apolipoproteins and apolipoprotein E genotype. J Lipid Res 41(11): $1812-1822$

18. Frikke-Schmidt R, Sing CF, Nordestgaard BG, Tybjaerg-Hansen A (2000b) Gender- and age-specific contributions of additional DNA sequence variation in the $5^{\prime}$ regulatory region of the APOE gene to prediction of measures of lipid metabolism. Hum Genet 115(4):331-345

19. Gamboa R, Vargas-Alarcon G, Medina-Urrutia A, CardosoSaldana G, Hernandez-Pacheco G, Zamora-Gonzalez J, PosadasRomero C (2001) Influence of the apolipoprotein E polymorphism on plasma lipoproteins in a Mexican population. Hum Biol 73(6):835-843
20. Grundy SM (1998) Hypertriglyceridemia, atherogenic dyslipidemia, and the metabolic syndrome. Am J Cardiol 81(4A):18B25B

21. Hallman DM, Boerwinkle E, Saha N, Sandholzer C, Menzel HJ, Csazar A, Utermann G (1991) The apolipoprotein E polymorphism: a comparison of allele frequencies and effects in nine populations. Am J Hum Genet 49(2):338-349

22. Hanley JA, Negassa A, Edwardes MD, Forrester JE. (2003) Statistical analysis of correlated data using generalized estimating equations: an orientation. Am J Epidemiol 157(4):364-375

23. Havel PJ (2004) Update on adipocyte hormones: regulation of energy balance and carbohydrate/lipid metabolism. Diabetes 53(Suppl 1):S143-S151

24. Heeren J, Beisiegel U, Grewal T (2006) Apolipoprotein E recycling: Implications for dyslipidemia and atherosclerosis. Arterioscler Thromb Vasc Biol 26:442-448

25. Hooper L, Summerbell CD, Higgins JP, Thompson RL, Capps NE, Smith GD, Riemersma RA, Ebrahim S (2001) Dietary fat intake and prevention of cardiovascular disease: systematic review. BMJ 322(7289):757-763

26. Howard BV, Lee ET, Yeh JL, Go O, Fabsitz RR, Devereux RB, Welty TK (1996) Hypertension in adult American Indians. The Strong Heart Study. Hypertension 28(2):256-264

27. Howard BV, Van Horn L, Hsia J, Manson JE, Stefanick ML, Wassertheil-Smoller S, Kuller LH, LaCroix AZ, Langer RD, Lasser NL, Lewis CE, Limacher MC, Margolis KL, Mysiw WJ, Ockene JK, Parker LM, Perri MG, Phillips L, Prentice RL, Robbins J, Rossouw JE, Sarto GE, Schatz IJ, Snetselaar LG, Stevens VJ, Tinker LF, Trevisan M, Vitolins MZ, Anderson GL, Assaf AR, Bassford T, Beresford SA, Black HR, Brunner RL, Brzyski RG, Caan B, Chlebowski RT, Gass M, Granek I, Greenland P, Hays J, Heber D, Heiss G, Hendrix SL, Hubbell FA, Johnson KC, Kotchen JM (2006) Low-fat dietary pattern and risk of cardiovascular disease: the women's health initiative randomized controlled dietary modification trial. JAMA 295(6):655666

28. Hu D, Jablonski KA, Sparling YH, Robbins DC, Lee ET, Welty TK, Howard BV (2002) Accuracy of lipoprotein lipids and apoproteins in predicting coronary heart disease in diabetic American Indians. The Strong Heart Study. Ann Epidemiol 12(2):79-85

29. Ikewaki K, Rader DJ, Zech LA, Brewer HB Jr (1994) In vivo metabolism of apolipoproteins A-I and $\mathrm{E}$ in patients with abetalipoproteinemia: implications for the roles of apolipoproteins B and E in HDL metabolism. J Lipid Res 35(10):1809-1819

30. Jones R (2003) Insulin resistance, diet and cardiovascular disease: a review. Food Agric Environ 1(1):26-29

31. Kamboh MI, Ferrell RE, Kottke B (1988) Genetic studies of human apolipoproteins. V. A novel rapid procedure to screen apolipoprotein E polymorphism. J Lipid Res 29(11):1535-1543

32. Kataoka S, Robbins DC, Cowan LD, Go O, Yeh JL, Devereux RB, Fabsitz RR, Lee ET, Welty TK, Howard BV (1996) Apolipoprotein $\mathrm{E}$ polymorphism in American Indians and its relation to plasma lipoproteins and diabetes. The Strong Heart Study. Arterioscler Thromb Vasc Biol 16(8):918-925

33. Kataoka SPM, Howard BV (1994) Simplified isoelectric focusing/immunoblotting determination of Apoprotein E phenotype. Clin Chem 401(1):11-13

34. Kuczmarski RJ, Carroll MD, Flegal KM, Troiano RP (1997) Varying body mass index cutoff points to describe overweight prevalence among U.S. adults: NHANES III (1988-1994). Obes Res 5(6):542-548

35. Lahoz C, Schaefer EJ, Cupples LA, Wilson PW, Levy D, Osgood D, Parpos S, Pedro-Botet J, Daly JA, Ordovas JM (2001) Apolipoprotein E genotype and cardiovascular disease in the framingham heart study. Atherosclerosis 154(3):529-537 
36. Lee E, Welty TK, Fabsitz R, Cowan LD, Le N, Oopik AJ, Cucchiara AJ, Savage PJ, Howard BV (1990) The Strong Heart Study: a study of cardiovascular disease in American Indians: design and methods. Am J Epidemiol 132(6):1141-1155

37. Lee ET, Welty TK, Fabsitz R, Cowan LD, Ngoc-Anh LE, Oopik AJ, Cucchiara AJ, Savage PJ, Howard BV (1990) The Strong Heart Study. A study of cardiovascular disease in American Indians: design and methods. Am J. Epidemiol 132:1141-1155

38. Lee RD, Nieman DC (1996) Nutritional assessment, Mosby

39. Lewis GF, Rader DJ (2005) New insights into the regulation of HDL metabolism and reverse cholesterol transport. Circ Res 96(12):1221-1232

40. Liese AD, Gilliard T, Schulz M, D'Agostino RB Jr, Wolever TM (2007) Carbohydrate nutrition, glycaemic load, and plasma lipids: the insulin resistance atherosclerosis study. Eur Heart J 28(1):8087

41. Lorgeril D (1997) The "diet-heart" hypothesis in secondary prevention of coronary heart disease. Eur Heart J 18:13-18

42. Ma Y, Li Y, Chiriboga DE, Olendzki BC, Hebert JR, Li W, Leung K, Hafner AR, Ockene IS (2006) Association between carbohydrate intake and serum lipids. J Am Coll Nutr 25(2):155163

43. Mahley RW, Innerarity TL, Rall SC Jr, Weisgraber KH (1984) Plasma lipoproteins: apolipoprotein structure and function. J Lipid Res 25(12):1277-1294

44. Mahley RW, Pepin J, Palaoglu KE, Malloy MJ, Kane JP, Bersot TP (2000) Low levels of high density lipoproteins in Turks, a population with elevated hepatic lipase. High density lipoprotein characterization and gender-specific effects of apolipoprotein e genotype. J Lipid Res 41(8):1290-1301

45. Mann J, Skeaff M, and Truswell S (2001) Dietary fats and prevention of cardiovascular disease. Conclusion may have been underplayed. Bmj 323(7319):1000-1001; author reply 10011002

46. Mitchell BD, Gonzalez Villalpando C, Arredondo Perez B, Garcia MS, Valdez R, Stern MP (1995) Myocardial infarction and cardiovascular risk factors in Mexico City and San Antonio. Texas. Arterioscler Thromb Vasc Biol 15(6):721-725

47. Mittendorfer B (2005) Sexual dimorphism in human lipid metabolism. J Nutr 135(4):681-686

48. Moll PP (1993) Genetics of atherosclerosis: some strategies for studies of apolipoprotein E. J Hum Biol 5:451-460

49. Mooradian AD, Haas MJ, Wong NC (2006) The effect of select nutrients on serum high-density lipoprotein cholesterol and apolipoprotein A-I levels. Endocr Rev 27(1):2-16

50. Mosher M (2002) Genetic architecture of plasma lipids in Siberian Buryat, In: Department of Anthropology, University of Kansas, Lawrence, KS, pp 174

51. Mosher MJ, Martin LJ, Cupples LA, Yang Q, Dyer TD, Williams JT, North KE (2005) Genotype-by-sex interaction in the regulation of high-density lipoprotein: the framingham heart study. Hum Biol 77(6):773-793

52. Nelson MR, Kardia SL, Ferrell RE, Sing CF (1999) Influence of apolipoprotein $\mathrm{E}$ genotype variation on the means, variances, and correlations of plasma lipids and apolipoproteins in children. Ann Hum Genet 63(Pt 4):311-328

53. NIH (1992) Triglyceride, high density lipoprotein, and coronary heart disease 10(2):1-28

54. North KE, Göring HH, Cole SA, Diego VP, Almasy L, Laston S, Cantu T, Howard BV, Lee ET, Best LG, Fabsitz RR, MacCleur JW (2006) Linkage analysis of LDL cholesterol in American Indian populations: the Strong Heart Family Study. J Lipid Res 47:59-66

55. North KE, Howard BV, Welty TK, Best LG, Lee ET, Yeh JL, Fabsitz RR, Roman MJ, MacCluer JW (2003) Genetic and environmental contributions to cardiovascular disease risk in
American Indians: the strong heart family study. Am J Epidemiol 157(4):303-314

56. Ordovas JM (2004a) The quest for cardiovascular health in the genomic era: nutrigenetics and plasma lipoproteins. Proc Nutr Soc 63(1): 145-152

57. Ordovas JM, Mooser V (2002) The APOE locus and the pharmacogenetics of lipid response. Curr Opin Lipidol 13(2):113117

58. Ordovas JM, Corella D (2004b) Genes, diet and plasma lipids: the evidence from observational studies, In: Ordovas A. P. S. a. J. M (ed) Nutrigenetics and Nutrigenomics, Karger, Basel, pp 41-76

59. Parks EJ, Krauss RM, Christiansen MP, Neese RA, Hellerstein MK (1999) Effects of a low-fat, high-carbohydrate diet on VLDL-triglyceride assembly, production, and clearance. J Clin Invest 104(8):1087-1096

60. Rader DJ (2006) Molecular regulation of HDL metabolism and function: implications for novel therapies. J Clin Invest 116(12):3090-3100

61. Rashid S, Patterson BW, Lewis GF (2006) Thematic review series: patient-oriented research. What have we learned about HDL metabolism from kinetics studies in humans? J Lipid Res 47(8):1631-1642

62. Ravnskov U (2002) A hypothesis out-of-date: the diet-heart idea. J Clin Epidemiol 55(11):1057-1063

63. Reilly M, Rader DJ (2006) Apolipoprotein E and coronary disease: a puzzling paradox. PLoS Med 3(6):e258

64. Reilly SL, Ferrell RE, Kottke BA, Kamboh MI, Sing CF (1991) The gender-specific apolipoprotein E genotype influence on the distribution of lipids and apolipoproteins in the population of Rochester, MN. I. Pleiotropic effects on means and variances. Am J Hum Genet 49(6):1155-1166

65. Reilly SL, Kottke BA, Sing CF (1990) The effects of generation and gender on the joint distributions of lipid and apolipoprotein phenotypes in the population at large. J Clin Epidemiol 43(9):921-940

66. Ribalta J, Halkes CJ, Salazar J, Masana L, Cabezas MC (2005) Additive effects of the PPARgamma, APOE, and FABP-2 genes in increasing daylong triglycerides of normolipidemic women to concentrations comparable to those in men. Clin Chem 51(5):864-871

67. Schakel SF, Sievert YA, Buzzard IM (1988) Sources of data for developing and maintaining a nutrient database. J Am Diet Assoc 88(10):1268-1271

68. Schlierf G, Arab L, Oster P (1983) Influence of diet on highdensity lipoproteins. Am J Cardiol 52(4):17B-19B

69. Schulz LO, Bennett PH, Ravussin E, Kidd JR, Kidd KK, Esparza J, Valencia ME (2006) Effects of traditional and western environments on prevalence of type 2 diabetes in Pima Indians in Mexico and the U.S. Diabetes Care 29(8):1866-1871

70. Sing C, Davignon J (1985) Role of the apolipoprotein E polymorphism in determining normal plasma lipid and lipoprotein variation. Am J Hum Genet 37(2):268-285

71. Sobel E, Papp JC, Lange K (2002) Detection and integration of genotyping errors in statistical genetics. Am J Hum Genet 70(2):496-508

72. Starc TJ, Shea S, Cohn LC, Mosca L, Gersony WM, Deckelbaum RJ (1998) Greater dietary intake of simple carbohydrate is associated with lower concentrations of high-density-lipoprotein cholesterol in hypercholesterolemic children. Am J Clin Nutr 67(6):1147-1154

73. Stengard JH, Clark AG, Weiss KM, Kardia S, Nickerson DA, Salomaa V, Ehnholm C, Boerwinkle E, Sing CF (2002) Contributions of 18 additional DNA sequence variations in the gene encoding apolipoprotein $\mathrm{E}$ to explaining variation in quantitative measures of lipid metabolism. Am J Hum Genet 71(3):501517 
74. Stevens J, Gautman SP, Keil JE (1993) Body mass index and fat patterning as correlates of lipids and hypertension in an elderly, biracial population. J Gerontol 48(6):M249-M254

75. Sun L, Wilder K, McPeek MS (2002) Enhanced pedigree error detection. Hum Hered 54(2):99-110

76. Utermann G, Weisgraber KH, Weber W, Mahley RW (1984) Genetic polymorphism of apolipoprotein E: a variant form of apolipoprotein E2 distinguished by sodium dodecyl sulfatepolyacrylamide gel electrophoresis. J Lipid Res 25(4):378-382

77. Weinberg SL (2004) The diet-heart hypothesis: a critique. J Am Coll Cardiol 43(5):731-733

78. Willett WC (2002) Dietary fat plays a major role in obesity: no. Obes Rev 3:59-68

79. Woods SC, Gotoh K, Clegg DJ (2003) Gender differences in the control of energy homeostasis. Exp Biol Med (Maywood) 228(10):1175-1180
80. Yang EJ, Chung HK, Kim WY, Kerver JM, Song WO (2003) Carbohydrate intake is associated with diet quality and risk factors for cardiovascular disease in U.S. adults: NHANES III. J Am Coll Nutr 22(1):71-79

81. Yannakoulia M, Yiannakouris N, Bluher S, Matalas AL, KlimisZacas D, Mantzoros CS (2003) Body fat mass and macronutrient intake in relation to circulating soluble leptin receptor, free leptin index, adiponectin, and resistin concentrations in healthy humans. J Clin Endocrinol Metab 88(4):1730-1736

82. Zoico E, Di Francesco V, Mazzali G, Vettor R, Fantin F, Bissoli L, Guariento S, Bosello O, Zamboni M (2004) Adipocytokines, fat distribution, and insulin resistance in elderly men and women. J Gerontol A Biol Sci Med Sci 59(9):M935-M939 